\title{
THE IMPACT OF THE HUMAN EYE'S PERCEPTION ON THE WALKABILITY OF STREET CANYONS
}

\author{
UDO DIETRICH \\ REAP research group (Resource Efficiency in Architecture and Planning), \\ HafenCity University Hamburg, Germany
}

\begin{abstract}
Walkability in cities is assessed in general at the neighbourhood scale (street grids and their connectivity, etc.) as well as at the street scale (width of sidewalks, existence of benches, etc.). The process of walking along a street canyon itself is hardly included in such investigations. This paper wants to contribute to the question of which physical conditions create a positive impression to make a street canyon attractive to walk along. The eye delivers a sharp vision only in the range of $2^{\circ}$ (the fovea). To generate a sharp image of the whole field of view, the eye scans it with quick movements (saccades) of mostly 4 to $15^{\circ}$ from one point of foveal view to the next one, and the brain completes the intermediate ranges to the final impression. The perception of what we see is facilitated if distinct objects are offered there, where saccades want to scan. In that case the saccades run smoothly creating the feeling that it is a pleasure to watch what is in the field of view, the object is perceived as interesting and diverse. This paper shows a series of figures where the pattern of a sequence of saccades is included in the view along typical street canyons. Because of the grazing angle of incidence of view on distant façades, three-dimensional modulated façades and their upper building lines attract saccades much better than two-dimensional modulated ones. Similarly, a linear upper building line hardly delivers attractions for the saccades, while a three-dimensional modulated one does it well. This paper includes recommendations for the size of three-dimensional objects to range from 0.5 up to $3 \mathrm{~m}$ for different distances.
\end{abstract}

Keywords: walkability of street canyons, visual perception, human eye, foveal view, saccades, extension of objects in the field of view, modern architecture and planning.

\section{INTRODUCTION}

Walking along a street (canyon) is part of the daily life of citizens. Optimally it should be a pleasure to walk in a city in general, not only for necessary transfers from home to work.

What makes a neighbourhood/a selected street walkable? Everybody will have its own criteria and there are several lists of indicators in the literature [1]-[5]. Generally, they all differentiate between the assessment of the neighbourhood (circa $500 \times 500 \mathrm{~m}$ ) and the single streets. For the neighbourhood, criteria like connectivity, diversity in land use, and population density can be used to derive a walkability index.

For the single streets, the basic aspect is that the pedestrian has to feel safe and the most important criteria are:

- a clear separation to fast moving objects (cars, bicycles);

- no negative sensory impressions like odour, unwanted people, bad maintenance;

- $\quad$ possibilities to flee (high number of crossroads or footpaths);

- $\quad$ sidewalks wide enough so that people can pass simultaneously;

- no obstacles, etc.

Further, there should be elements that invite to walk along, for example:

- $\quad$ easy to access and to leave: public travel stations nearby (up to $500 \mathrm{~m}, 5$ to $10 \mathrm{~min}$ to walk);

- $\quad$ flat walk, no strong gradient; 
- lower building line continues quite straight and visible, without interruptions or displacements (Fig. 1);

- $\quad$ benches and places to stay and communicate, bike racks;

- if ground floors are public: visible retail, cafes and restaurants (with terraces);

- if ground floors are private: transition zones (front gardens, terraces or steps) for communication as well as keeping distance [6];

- children's playgrounds, lawn, fields for exercises and other activities.

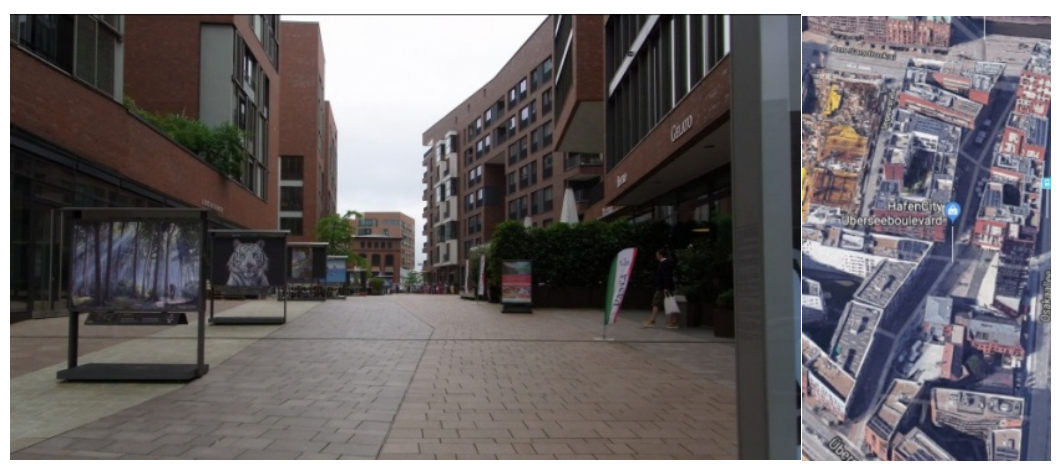

(a)

(b)

Figure 1: Sub-centre of HafenCity Hamburg ("Ueberseeboulevard"). The pedestrian zone has a notable slope. The lower building line is hidden through projecting buildings. Buildings are displaced, retail in ground floors is hardly visible. (a) Picture: Author's own; (b) 3D view right. (Source: Google Maps.)

Supplementary offers that enable visitors to enjoy walking through the street will make the street a real hot spot:

- $\quad$ human scale/feeling of secureness, ratio street width to building height about 2:1 to $1: 1$, or intermediate elements (trees, pavilions, or kiosks) to translate from high buildings down to a human scale;

- a clear beginning and end of the walking tour (crossroad, retail, plaza, etc.);

- $\quad$ street trees;

- to watch resting and moving people while walking;

- diverse and aesthetic façades;

- Gehl [6] notes that our brain is asking for new (optical) information each 5 to $10 \mathrm{~s}$ combined with the pedestrian's velocity of $5 \mathrm{~km} / \mathrm{h}(1.4 \mathrm{~m} / \mathrm{s})$ that leads to the conclusion that façades should have vertical separations, especially in the ground floors, every 10 to $15 \mathrm{~m}$.

On the contrary to people that rest on a place, the perception for a person walking along a street is different on some critical aspects:

- the objects to observe are at different distances;

- there is no static view, yet the elements (left and right) are moving and changing across time while the observer is moving forwards;

the view is concentrated along the street canyon, and the elements (façades, persons, trees, etc.) are drifting left and right in the view, and out of sight. 


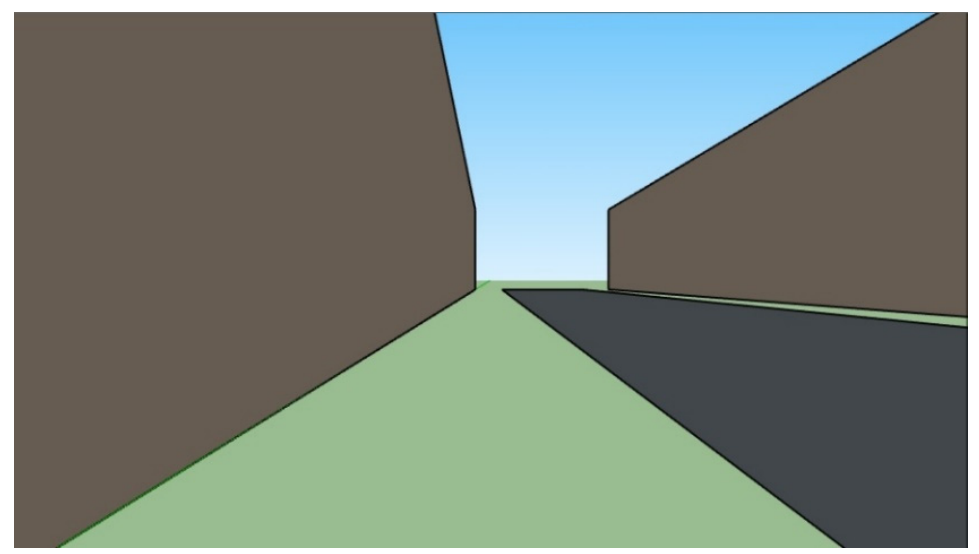

Figure 2: View along a street canyon. Street width $25 \mathrm{~m}$, building height $15 \mathrm{~m}$. The person is standing $2.75 \mathrm{~m}$ off the left façade on the sidewalk, length of buildings $200 \mathrm{~m}$. (Source: Created by the author using Google SketchUp.)

For the investigation a typical (European) urban street canyon is chosen with a width of $25 \mathrm{~m}$ (two-lane street and sidewalks) and a building height of $15 \mathrm{~m}$ (5 storeys). Fig. 2 shows what we see when looking along that canyon. The field of view of the human eye is like a flattened funnel, with around 45 to $55^{\circ}$ left and right horizontally, about $25^{\circ}$ upwards, and $35^{\circ}$ downwards. In total that ends with a field of view that corresponds roughly to a rectangle with a side ratio of 16:9. For that reason, screens were adapted to that ratio in spite of the fact that this would only make sense if the screen fills the whole field of view. Normally, a screen or another object at which we look is only a (small) part of the field of view. Only then we can recognize details like letters and faces. For such objects, the golden cut (1.61:1 or to be comparable 14.6:9) is well accepted as the preferred ratio.

In Hillnhütter [7] is stated, that so more attractive the view on the façades and elements in a street canyon is, so more we like walking along it and so shorter is the perceived time to pass through. This paper investigates which objects are in the field of view in a street canyon and - without asking for their design - which size they have to have to be perceived generally. That relates the size of objects with attractiveness and thus walkability of a street canyon and wants to be a valuable contribution to a sustainable city.

The main objective of this paper is to add two criteria to the list of offers that enable visitors to enjoy walking through the street (above, after Fig. 1):

- the vertical modulation of façades should better be 3D (with elements) rather than 2D (with colour/material);

- the diversity of the upper building line is an important element for the aesthetics and walkability of a street canyon.

In Section 2 the perception of the human eye is analysed based on literature, the main finding is that the eye scans the field of view stepwise in so called saccades. There, where a saccade is watching for information, should be a distinct object - the detection is easy and perceived as pleasurable and attractive. In Section 3 that pattern of saccades is transferred to the view along the street canyon and the optimal size of objects in façades and the upper building line can be derived and summed up in rules. Section 4 finishes with a few comments to contemporary architecture that neglects these rules often with its tendency to minimalism. 


\section{THE PERCEPTION OF THE HUMAN EYE}

\subsection{The foveal view and the saccades}

The image that we see is a product of the genius combination of the eye as an optical instrument and the brain. The human eye is a sphere of about $45 \mathrm{~mm}$ diameter with a lens in front. The backside receives the information from the lens. For physical reasons, with only one lens the image is bottom up. The brain turns it $180^{\circ}$. That has the advantage that one lens is enough and allows nature to spare extended objectives that would not fit inside the head. It has the speciality (disadvantage) that the whole perception becomes subjective, it is influenced by the brain, is based on personal experience and thus might be different for different persons.

The receiver on the backside of the eye is not flat like in a camera but spherical. Again, for physical reasons, there exists one single point where the image is sharp: exactly opposite to the lens. In that point, the fovea is the highest concentration of cones for colour perception (corresponding to about 4 million pixels, a compact camera has about 20 million now). The lens has a light gathering ability $\mathrm{f} / 3.5$ and a focal length of $44.5 \mathrm{~mm}$ (corresponding to a low range of a standard zoom in a camera).

The sharp range in the fovea has an extension in the human view of only 1 to $2^{\circ}$. The light coming from all other parts of the view becomes less and less sharp, and less and less coloured, see Fig. 3.

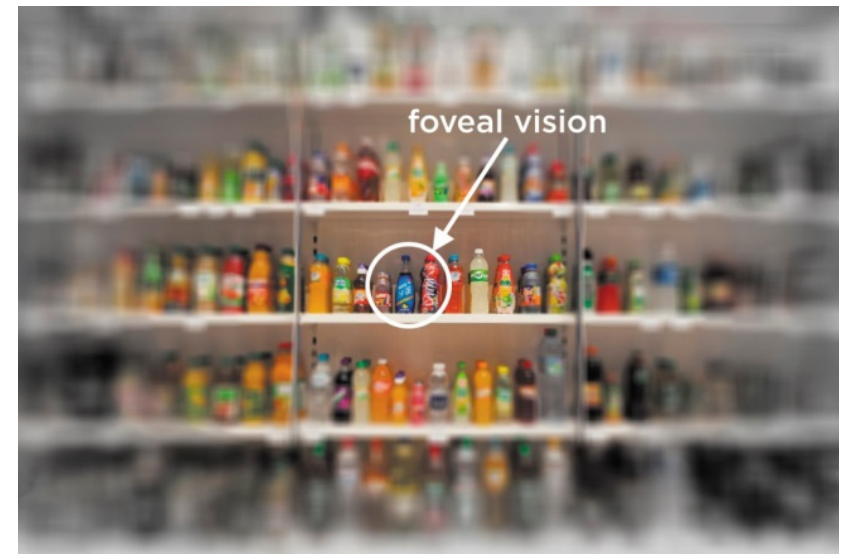

Figure 3: The foveal vision of the human eye without further completion of the brain (the image would be supplementary bottom up) [8].

The brain complements the missing information to a sharp image in the whole field of vision. To reach that, the eye changes its position in fast movements to bring a nearby point into the sharp vision of the fovea. These movements are called saccades. They avoid also that the muscles in the eye stay in the same tension and thus to avoid visual fatigue and they help to reshape the view again and again.

We do saccades each $0.2-0.6 \mathrm{~s}$ (until $2 \mathrm{~s}$ ) resulting in 10 to 15 fixations in $5 \mathrm{~s}$, the angle of movement from one to the next is mostly in the range between 4 and $15^{\circ}$ (up to 20 $0^{\circ}$ [9].

Finally, the complete image is composed of single patches comparable to a Polaroid picture from David Hockney and finally smoothed by the brain (see Fig. 4). 


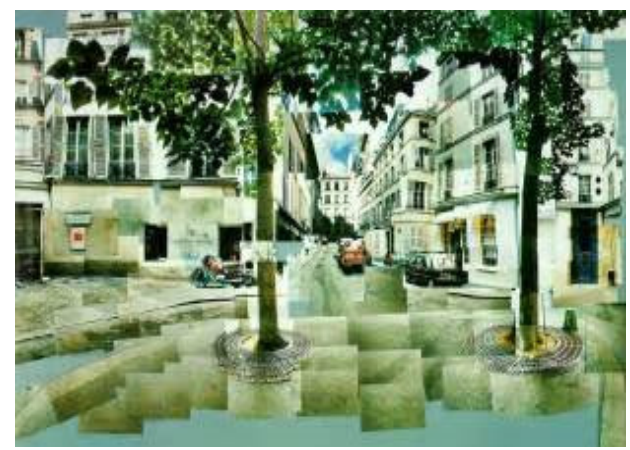

(a)

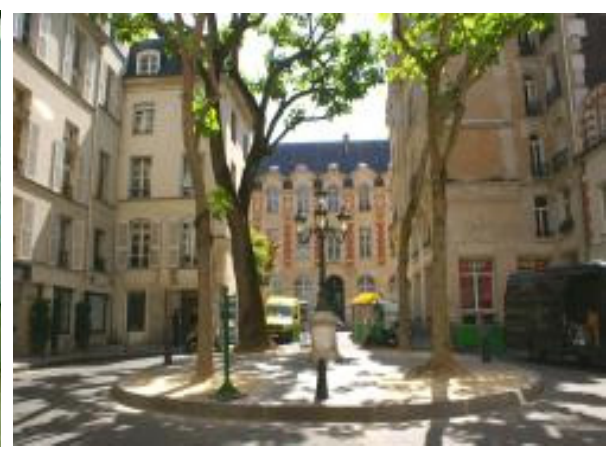

(b)

Figure 4: Illustration of the interacting between the human eye with saccades and the brain. A patchwork of information is taken by the eye's saccades (like (a) the work of David Hockney, Place Furstenberg Paris, 1985 [10]) and (b) the final smoothing by the brain (like in the photography of the same place [11]).

\subsection{Brain-controlled scanning of objects under investigation}

Each object that is investigated by the human eye is scanned with saccades. If we read a text, the eye is guided externally line by line, jumping from word to word and line to line, sometimes also backwards for better understanding. In the foveal (sharp) view are only about 4 to 5 letters. To understand a text, the brain needs only a few pieces of information about a whole word and it completes missing (not sharply seen) parts, based on experience (Fig. 5).

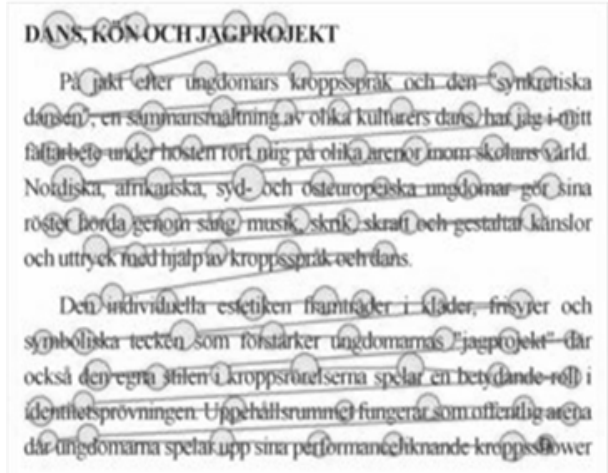

(a)
For taht rosaen we can raed and udnernsntad qiute esay a txet wehre olny the fsrit and the lsat letetr are in the cerocrt oedrr.

Figure 5: Reading a text. (a) Illustration of the saccades jumping from word to word, mostly forwards, sometimes backwards. The brain completes the fragmented information to the full text based on experience and knowledge of the words [12]; (b) We can read a text where only the first and the last letter are in the correct order without big problems - the brain complements the missing information. 
If there is to generate well-defined information about the observed object, the saccades become internally, brain-controlled guided (see Fig. 6).
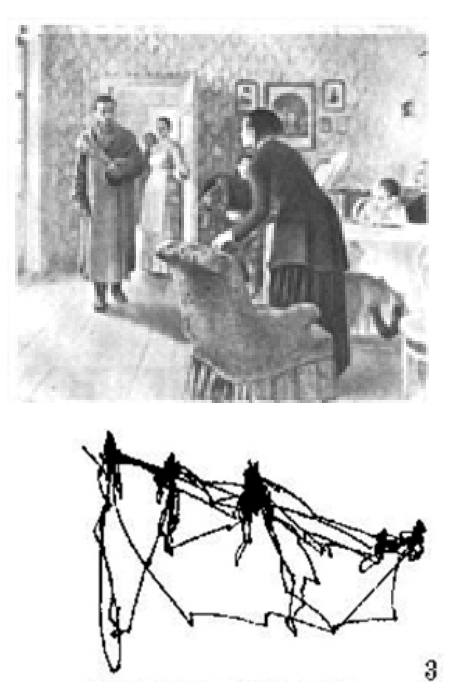

Give the ages of the people

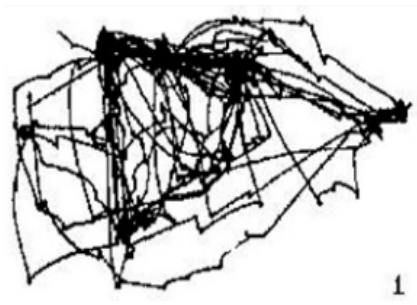

Free examination

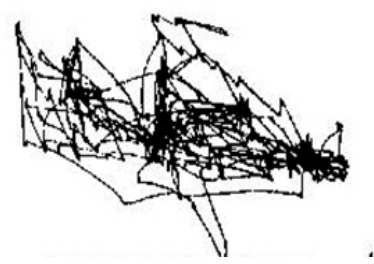

Surmise what the family had been doing before the arrival of the unexpected visitor

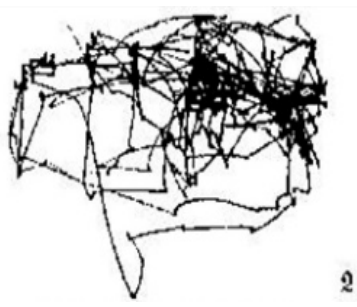

Estimate material circumstances of the family

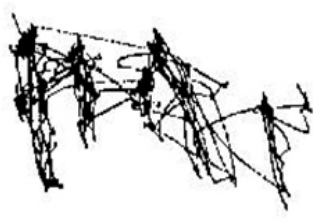

Remember the clothes worn by the people

Figure 6: Illustration of brain-controlled saccades if the observation is related to an intellectual task (pictures 2 to 5); picture one shows the free examination [13].

\subsection{Free examination of objects}

The unguided, free examination (see picture 1 in Fig. 6) follows eye-catching geometrical structures and contrasts in shape and colour. That is how we look at pictures, façades and along street canyons. Paintings are made to be aesthetic, much more than urban elements. Of course, paintings have an objective and show also aspects of human/social behaviour. There is no doubt about the most famous paintings, either for a skilled art critic or if foot voting, since the two cases select the same paintings (Fig. 7). This happens in all historical periods, except in contemporary art, where specialists and laypersons do not coincide.

There are different opinions about if the urban arrangement at rue de Rivoli with the Louvre is attractive enough to invite to walk along but there is no doubt that the Mona Lisa inside is an aesthetical highlight in painting.

The eye moves over the painting, from element to element. The most comfortable situation would be if the eye is unconsciously guided by these elements in a way that the path of saccades captures the whole area, following lines and diagonals. The path should be guided every time from the outer parts of the painting back to the inner parts. The eye should never stop at a dead end not knowing where to continue plus it should never fall out of the painting.

If all that would be fulfilled the eye could run smoothly over the painting and analyse it very comfortably. In total, it would be a pure pleasure to investigate all that hidden lines and correlations between the elements - what a nice painting! 


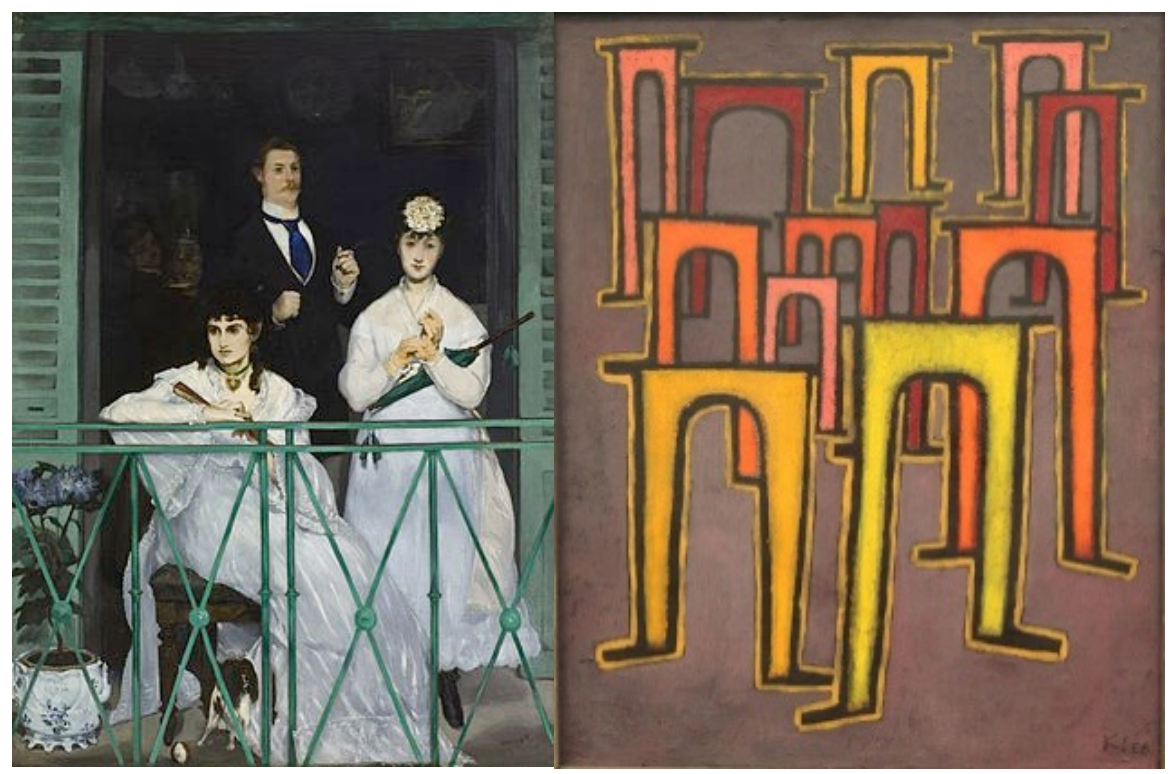

(a)

(b)

Figure 7: Examples of paintings that are well accepted as highly aesthetical, independent of their style as more realistic or even abstract. (a) Edouard Manet, The balcony, 1868, Musee d'Orsay, Paris [14]; (b) Paul Klee, Revolution of the viaduct, 1937, Hamburger Kunsthalle [15].

It can be concluded that objects that are easy to scan are perceived as balanced, interesting, dynamic, nice and aesthetical. It may be that the whole composition of that objects follows a (hidden) pattern and this makes it very easy for the eye to follow these structures.

\section{OPTICAL PERCEPTION OF STREET CANYONS}

\subsection{Saccades on the field of view straight along a street canyon}

The first task for a successful walk along a street canyon is to secure the way, to observe if there are obstacles on the ground level, other people walking in the opposite or same direction. This requires that we look straightforward most of the time and only occasionally to the right or left. The foveal view falls in the vanishing point, the field of view is scanned with saccades. Fig. 8 shows a possible pattern of hypothetical saccades in the typical range between 4 and $15^{\circ}$ and it can be seen that a remarkable part of the field of view (containing the sky and very far objects) does not deliver helpful information for the saccades.

The view left and right would meet the façades nearly perpendicularly and their diversity and aesthetics could be enjoyed. The view straightforward allows only a view on the façades in a small, grazing angle, where details are hardly recognizable. Unmodulated façades like in Fig. 8 do not further deliver a helpful guidance for the saccades.

The same situation but with façades that are 3D-modulated each $10 \mathrm{~m}$ (representing different buildings or vertical separations) is shown in Fig. 9. Here the modulation is clearly visible also for distant parts of the façades and delivers a lot of interesting points to attract the saccades plus to scan the view - we feel attracted by that view and enjoy walking along. 


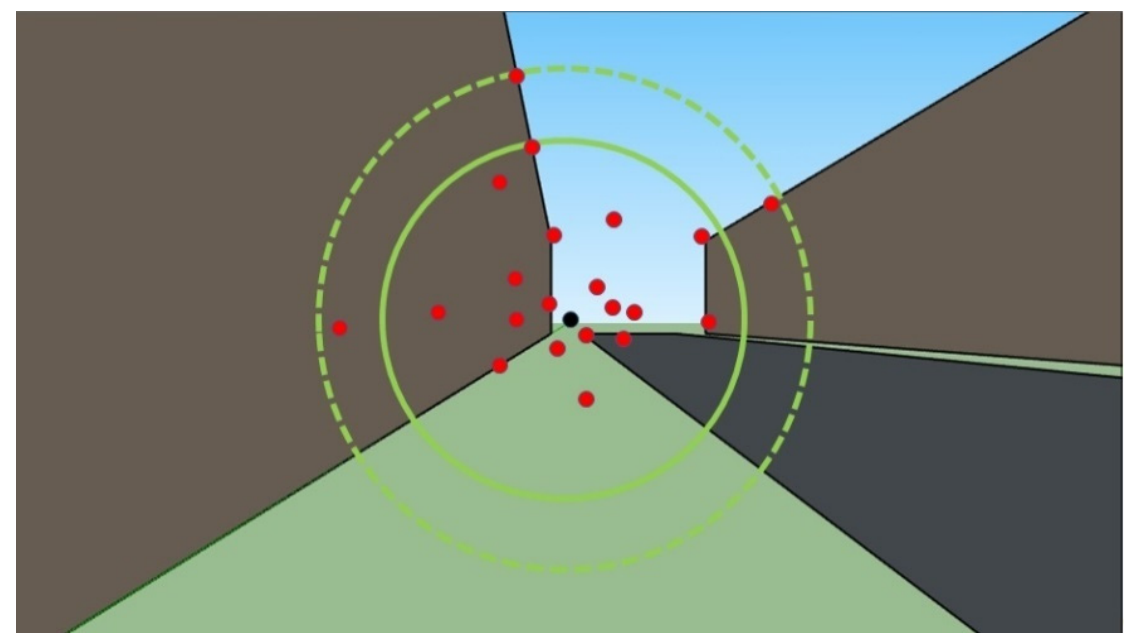

Figure 8: An illustration of the view straightforward in a street canyon with unmodulated façades. The field of view is scanned by saccades (red points) and the vanishing point is marked in black. Saccades are in a range of $15^{\circ}$ around it (green circle), rarely extended to $20^{\circ}$ (dashed green circle). (Source: Created by the author using Google SketchUp.)

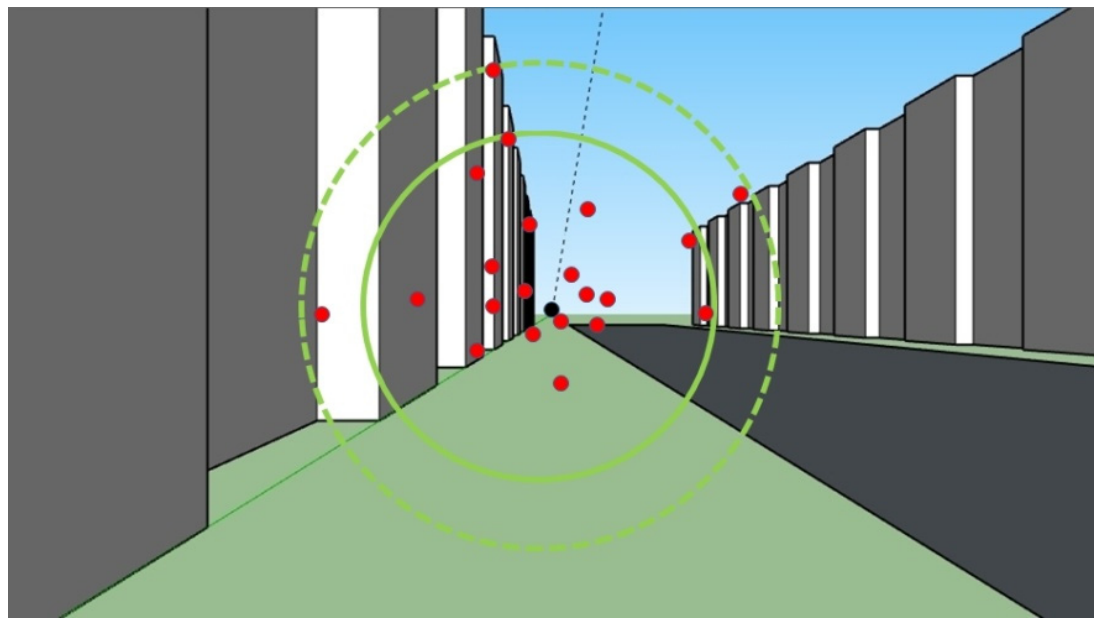

Figure 9: An illustration of the view straightforward in a street canyon with façades that are 3D-modulated each $10 \mathrm{~m}$. For further explanations, see Fig. 8. (Source: Created by the author using Google SketchUp.)

Fig. 10 shows again the same view but for façades that are 2D-modulated and differ in colour but not in shape. Especially for the distant part of the façades (thus in the central direction of view!) differentiation of coloured façades becomes more and more difficult, therefore saccades are less attracted and guided. A street with such façades is interesting for the look left and right but less for the view straightforward. 


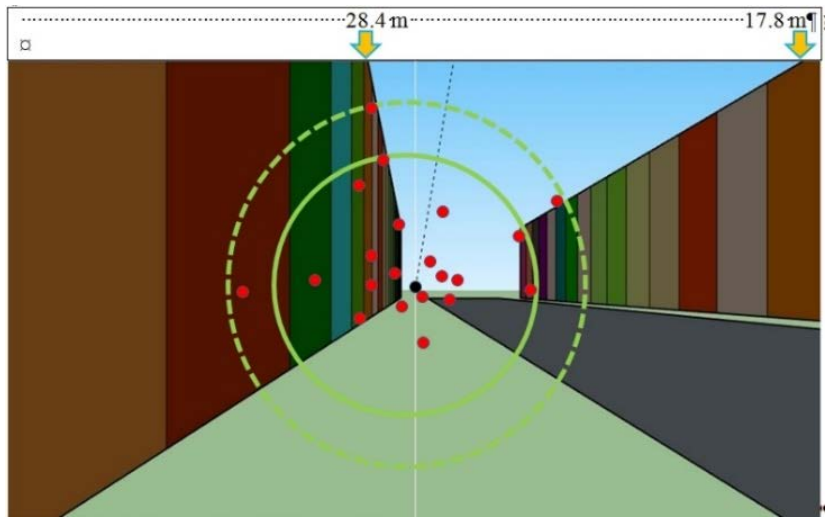

Figure 10: An illustration of the view straightforward in a street canyon with façades that are 2D-modulated in colour each $10 \mathrm{~m}$. Red arrows show the distance in front where the upper building line moves in the field of view. For further explanations, see Fig. 8. (Source: Created by the author using Google SketchUp.)

Further it is helpful to investigate where which part of the canyon is in the field of view. In Figs 2, 8, 9 and 10 the person is standing at the beginning of a $200 \mathrm{~m}$ long street canyon (that is large and chosen only to illustrate the effects optimally; street grids have a typical length of about 50 to $100 \mathrm{~m}$ ) and $2.75 \mathrm{~m}$ off (on the sidewalk) the left façade. Because of the $45^{\circ}$ view left and right the eye looking along the canyon does not see the façades that are immediately but only the façade $2.75 \mathrm{~m}$ (left) and $22.25 \mathrm{~m}$ (right) in front, respectively (see Fig. 11). To see the façades placed immediately left and right, we have to turn the head!

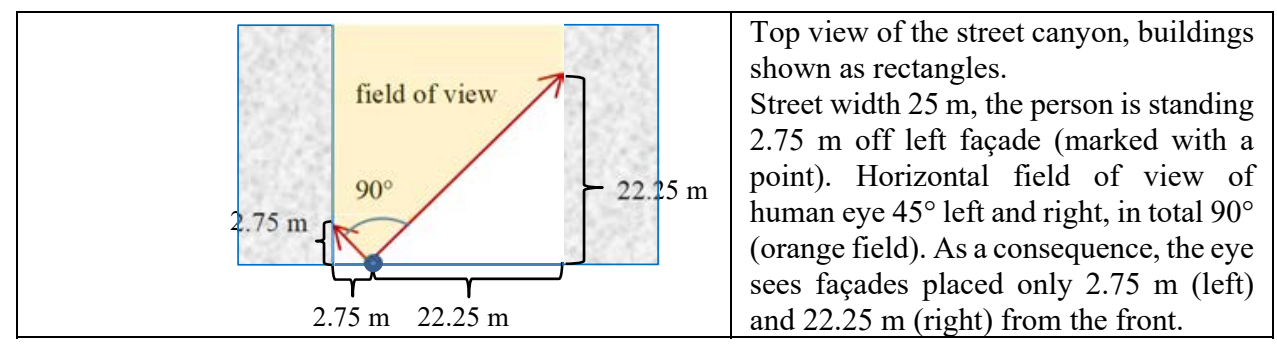

Figure 11: Horizontal field of view of the human eye in a street canyon with $25 \mathrm{~m}$ width, the person is standing $2.75 \mathrm{~m}$ off the left façade.

For the vertical observation, the first part of the field of view left and right is filled completely with the façades. With a short calculation in spherical coordinates and the height of the field of view of $25^{\circ}$, it can be derived with an eye height of $1.7 \mathrm{~m}$ above ground that the upper building line becomes visible at $28.4 \mathrm{~m}$ (left) and $17.8 \mathrm{~m}$ (right), see Fig. 10. That means that in the central part of the field of view, the upper building line becomes a decisive element for the task to attract and guide saccades. For that reason, the upper building line should be modulated richly in 3D. Fig. 10 demonstrates an unmodulated upper building line, while Fig. 9 a slightly modulated upper building line. 


\subsection{Recommended size of objects on the field of view}

To investigate the best modulation of objects (upper building line as well as façades) in the field of view along a street canyon, a simplified calculation is helpful, see Fig. 12. An object that is observed from far must have a minimal extension to be perceived in the foveal view. For the view straightforward along the street canyon, saccades scan the field of view in angles of $4^{\circ}$ to $15^{\circ}$ (partly $20^{\circ}$ ) and the view strikes in a certain distance on the façade/upper building line. The combination of both pieces of information delivers a recommendation for the extension of objects in the field of view along a street canyon (results are shown in Table 1). Objects should have a size of $0.5 \mathrm{~m}$ minimum for the ones nearest in the field of view, up to 4 to $5 \mathrm{~m}$ for the most distant ones (thus, for the upper line, about one storey).

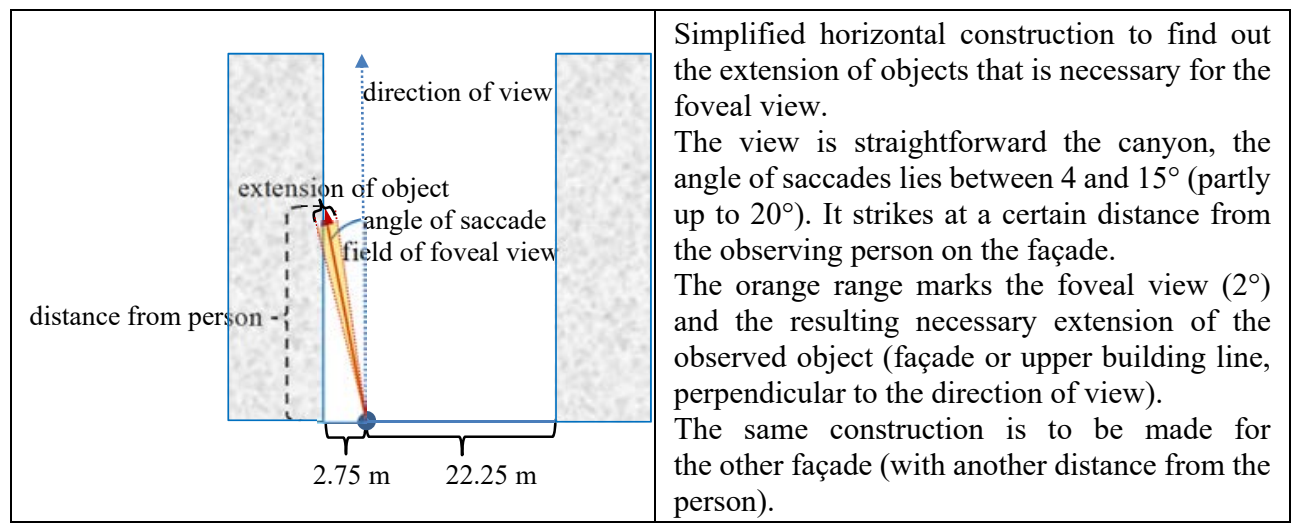

Figure 12: Simplified horizontal construction to find out the extension of objects that is necessary for the foveal view.

Table 1: Extension of objects (in façades/upper building line) that is necessary to be perceived in foveal view regarding their distance from the observing person. The distance is determined by the saccades out of the view straightforward (Fig. 12).

\begin{tabular}{|c|c|c|c|c|c|}
\hline Angle of saccade out of view straightforward $\left(^{\circ}\right)$ & 4 & 8 & 12 & 16 & 20 \\
\hline \multicolumn{6}{|l|}{ Left façade (distance $2.75 \mathrm{~m}$ ) } \\
\hline $\begin{array}{l}\text { Distance where façade/upper building line is stricken } \\
\text { (m) }\end{array}$ & 39 & 20 & 13 & 10 & 8 \\
\hline $\begin{array}{l}\text { Necessary extension of objects to be perceived in } \\
\text { foveal view }(\mathrm{m})\end{array}$ & 1.4 & 0.7 & 0.5 & 0.3 & 0.3 \\
\hline \multicolumn{6}{|l|}{ Right façade (distance $22.25 \mathrm{~m}$ ) } \\
\hline $\begin{array}{l}\text { Distance where façade/upper building line is stricken } \\
\text { (m) }\end{array}$ & 325 & 162 & 107 & 80 & 62 \\
\hline $\begin{array}{l}\text { Necessary extension of objects to be perceived in } \\
\text { foveal view }(\mathrm{m})\end{array}$ & 11.4 & 5.7 & 3.7 & 2.8 & 2.2 \\
\hline
\end{tabular}

Because the walking person is moving forward in the canyon, that rule has to be fulfilled everywhere. That means, that the smallest objects must be the most frequent while the bigger ones less. Such a frequency rule is also known from morphologies, for examples in street 
grids [16], where the small streets are the most frequent ones, followed by middle ones, and finally, a few big axes to organize traffic at larger scale.

Fig. 13 shows pictures of different types of upper building lines. The left one shows on the left side, an upper building line that is rich in modulation, objects are in different sizes including very big ones - a pleasure for the eye to observe; where the saccades find a target and are guided along the building line. While the right side shows an upper building line that has only a few modulations. Especially smaller objects are missing, the building line is not continuous but displaced. The eye is not guided; saccades hardly find an object to fix. The right picture shows continuous building lines but nearly completely without modulations. Even if the eye is not irritated by displacements, the saccades cannot find objects, and the most attractive ones are the two lamps hanging in the middle of the street.

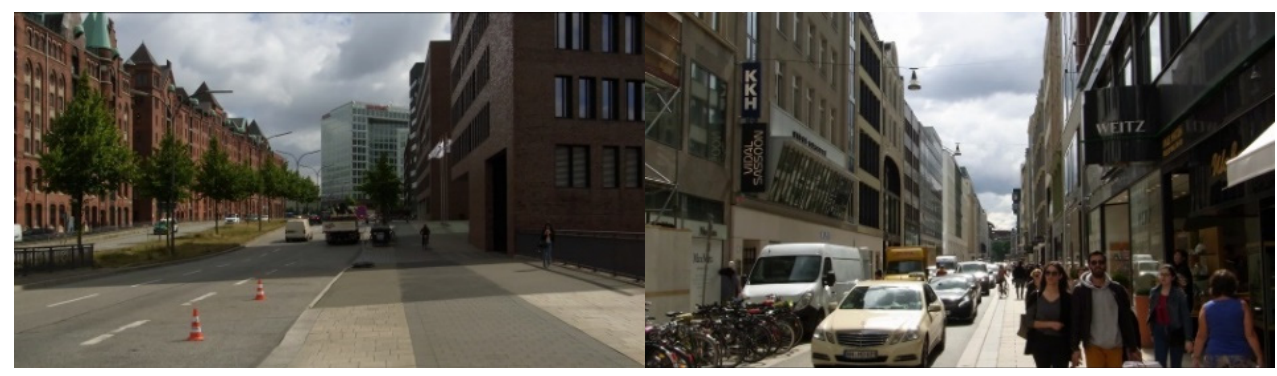

Figure 13: Examples of street canyons with different upper building lines.

\subsection{Importance of trees in street canyons}

Single trees - if fully grown - can also act as objects that attract and guide saccades. Especially if they are planted in continuous rows they hide façades as well as upper lines (if the buildings are not too high), see Fig. 14. That might hinder the view to well designed and modulated objects but helps also to improve the situation remarkably if that is not the case.

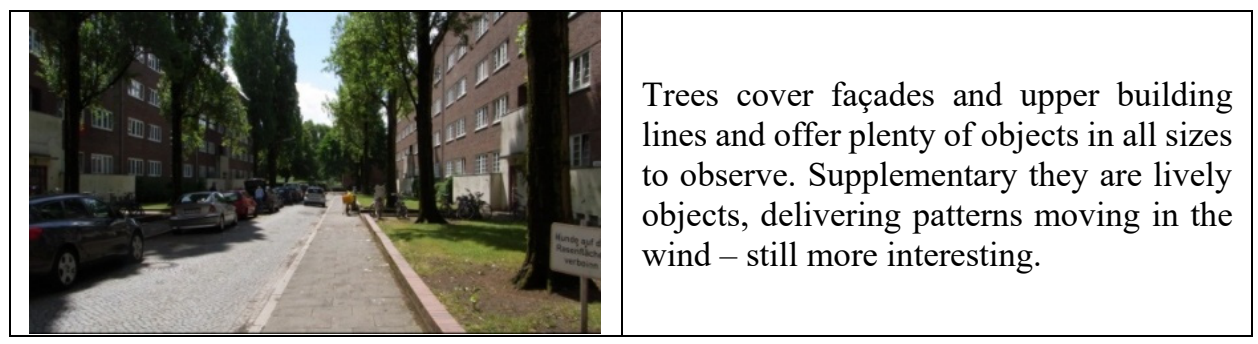

Figure 14: Rows of (fully grown) trees in a street canyon - they are dominant in the view and deliver objects in all sizes, attracting and guiding saccades. (Source: Author.)

Trees have furthermore several advantages, they create a clear separation to fast-moving cars, reduce noise and heat, act as a place where animals can exist, protect against sun and wind, and are in principle a pleasure to observe. 


\section{FINAL REMARKS}

Contemporary architecture follows a trend, where buildings are regarded as self-related, single objects. The respect to their shape and arrangement in regard to the neighbour buildings has become less important and is generated partly by coincidence (see Fig. 13, left picture and buildings on the right-hand side). The idea that buildings in a street form a higher identity has become less important or is neglected. That tendency reduces the positive perception of street canyons and thus walkability of our quarters. Modern architecture should discover again the meaning of a "we" instead of a "me" in the design of a building that is in a spacial relation with others.

\section{REFERENCES}

[1] Cain, K.L., Millstein, R.A. \& Geremia, C.M., Microscale Audit of Pedestrian Streetscapes (MAPS): Data Collection \& Scoring Manual. http://sallis.ucsd.edu/ Documents/Measures_documents/MAPS\%20Manual_v1_010713.pdf. Accessed on: 20 Jul. 2018.

[2] Living Streets, www.livingstreets.org.uk/. Accessed on: 20 Jul. 2018.

[3] Frank, L.D. et al., The development of a walkability index: Application to the Neighborhood Quality of Life Study. British Journal of Sports Medicine, 44(13), pp. 924-933, 2010.

[4] Hajrasouliha, A. \& Lin, Y., The impact of street network connectivity on pedestrian volume. Urban Studies 52(13), pp. 2483-2497, 2015.

[5] Institut für Stadtplanung Und Städtebau. Messung und Erfassung der Fussgängerfreundlichkeit von Stadträumen, 2017. www.uni-due.de/imperia/md/ content/staedtebau/messung_und_erfassung_der_fu $\% \mathrm{C} 3 \% 9 \mathrm{Fg} \% \mathrm{C} 3 \% \mathrm{~A} 4$ ngerfreundli chkeit_in_essen_2017_xs.pdf. Accessed on: 30 Jul. 2018

[6] Gehl, J., Life between Buildings, Van Nostrand Reinhold: New York, 1987.

[7] Hillnhütter, H., Pedestrian Access to Public Transport, University of Stavanger, 2016.

[8] Eye Tracking Competence Center, Visual field and visual range, Switzerland. http://eyetracking.ch/wordpress/wp-content/uploads/2014/01/Gesichtsfeld-

Sehbereich-mit-EyeTracking-in-Usability-Tests.jpg. Accessed on: 2 May 2017.

[9] Hasse, C., Blickbewegungen auf Fassaden, Shaker: Aachen, 2012.

[10] Hockney, D., Place Furstenberg, Paris, 1985. http://3.bp.blogspot.com/8MTV9ouBBDI/UQeMNhBo_II/AAAAAAAAWE0/WE3n4vdQF4s/s1600/hockney -furstenberg-paris.jpg. Accessed on: 20 May 2017.

[11] TripAdvisor, Place de Furstenberg. www.tripadvisor.de/Attraction_Review-g187147d191148-Reviews-Place_Furstenburg-Paris_Ile_de_France.html.

[12] Bielefeld University, Augenbewegungen und visuelle Aufmerksamkeit. www.techfak.uni-bielefeld.de/ ihkoesli/vab2011/07-vab2011-hk-augenbewegungensw.pdf. Accessed on: 2 May 2017.

[13] Chapter 4: Human Vision. https://mafiadoc.com/chapter-4-human-vision 5a1c72991723dd32b4b853d1.html. Accessed on: 30 Jul. 2019.

[14] Musee d'Orsay, Edouard Manet: Le balcon. www.musee-orsay.fr/de/kollektionen/ werkbeschreibungen/gemaelde/commentaire_id/der-balkon-8495.html?cHash $=\mathrm{dd} 5 \mathrm{a} 5 \mathrm{~d} 3954$. Accessed on: 21 Jul. 2018.

[15] Hamburger Kunsthalle, Paul Klee: Revolution Of The Viaduct, 1937. www.hamburger-kunsthalle.de/sammlung-online/paul-klee/revolution-des-viaductes. Accessed on: 21 Jul. 2018

[16] Urban Morphology \& Complex Systems Institute, Paris.

www.urbanmorphologyinstitute.org/. Accessed on: 23 Jul. 2018. 